\title{
A Quantitative Analysis of Factors Influencing Organic Matter Concentration in the Topsoil of Black Soil in Northeast China Based on Spatial Heterogeneous Patterns
}

\author{
Zhenbo Du ${ }^{1}$, Bingbo Gao ${ }^{1,2,3, *}$, Cong Ou ${ }^{1}\left(\mathbb{D}\right.$, Zhenrong Du ${ }^{1}\left({ }^{\infty}\right.$, Jianyu Yang ${ }^{1,2}$, Bayartungalag Batsaikhan ${ }^{4}$, \\ Battogtokh Dorjgotov ${ }^{4}$, Wenju Yun ${ }^{2}$ and Dehai Zhu ${ }^{1,2}$ \\ 1 College of Land Science and Technology, China Agricultural University, Tsinghua East Road, \\ Beijing 100083, China; tufangbobo@cau.eud.cn (Z.D.); oucong@cau.edu.cn (C.O.); \\ duzhenrong@cau.edu.cn (Z.D.); ycjyyang@cau.edu.cn (J.Y.); zhudehai@cau.edu.cn (D.Z.) \\ 2 Key Laboratory of Agricultural Land Quality (Beijing), Ministry of Natural Resources of China, \\ Beijing 100083, China; yunwenju@lcrc.org.cn \\ 3 Beijing Research Center for Information Technology in Agriculture, Beijing Academy of Agriculture and \\ Forestry Sciences, 11 Shuguang Huayuan Middle Road, Haidian District, Beijing 100097, China \\ 4 Institute of Geography and Geoecology, Mongolian Academy of Sciences, Ulaanbaatar 15170, Mongolia; \\ bayartungalag_b@mas.ac.mn (B.B.); dbattogtokh@mas.ac.mn (B.D.) \\ * Correspondence: gaobingbo@cau.edu.cn
}

\section{check for} updates

Citation: Du, Z.; Gao, B.; Ou, C.; Du, Z.; Yang, J.; Batsaikhan, B.; Dorjgotov, B.; Yun, W.; Zhu, D. A Quantitative Analysis of Factors Influencing Organic Matter Concentration in the Topsoil of Black Soil in Northeast China Based on Spatial Heterogeneous Patterns. ISPRS Int. J. Geo-Inf. 2021, 10, 348. https:// doi.org/10.3390/ijgi10050348

Academic Editor: Wolfgang Kainz

Received: 1 April 2021

Accepted: 16 May 2021

Published: 18 May 2021

Publisher's Note: MDPI stays neutral with regard to jurisdictional claims in published maps and institutional affiliations.

Copyright: (c) 2021 by the authors. Licensee MDPI, Basel, Switzerland. This article is an open access article distributed under the terms and conditions of the Creative Commons Attribution (CC BY) license (https:// creativecommons.org/licenses/by/ $4.0 /)$.
Abstract: Black soil is fertile, abundant with organic matter $(\mathrm{OM})$ and is exceptional for farming. The black soil zone in northeast China is the third-largest black soil zone globally and produces a quarter of China's commodity grain. However, the soil organic matter (SOM) in this zone is declining, and the quality of cultivated land is falling off rapidly due to overexploitation and unsustainable management practices. To help develop an integrated protection strategy for black soil, this study aimed to identify the primary factors contributing to SOM degradation. The geographic detector, which can detect both linear and nonlinear relationships and the interactions based on spatial heterogeneous patterns, was used to quantitatively analyze the natural and anthropogenic factors affecting SOM concentration in northeast China. In descending order, the nine factors affecting SOM are temperature, gross domestic product (GDP), elevation, population, soil type, precipitation, soil erosion, land use, and geomorphology. The influence of all factors is significant, and the interaction of any two factors enhances their impact. The SOM concentration decreases with increased temperature, population, soil erosion, elevation and terrain undulation. SOM rises with increased precipitation, initially decreases with increasing GDP but then increases, and varies by soil type and land use. Conclusions about detailed impacts are presented in this paper. For example, wind erosion has a more significant effect than water erosion, and irrigated land has a lower SOM content than dry land. Based on the study results, protection measures, including conservation tillage, farmland shelterbelts, cross-slope ridges, terraces, and rainfed farming are recommended. The conversion of high-quality farmland to non-farm uses should be prohibited.

Keywords: black soil; geographical detector; soil organic matter; influencing factors

\section{Introduction}

Black soil is one of the most valuable resources available to human beings because it is abundant with OM and superior for farming [1]. The black soil zone in northeast China is the third-largest black soil zone globally and serves as China's warehouse [2]. It produces a quarter of China's commodity grain each year and plays a significant role in ensuring food security for the Chinese population of 1.4 billion. However, the soil organic matter (SOM) in this zone is declining, and the quality is decreasing due to overexploitation and unsustainable farming practices. Reduced SOM in the tillage layer is one of the primary reasons for the degradation of black soil. The SOM loss rate is severe; it is estimated that 
China loses about one centimeter of black soil annually. That loss requires 200 to 400 years for the soil to recover [3].

In response to this crisis, China launched a plan to protect black soil in the northeast region from 2017 to 2030 to promote the sustainability of resources utilization, ecological environment, and productive capacity of black soil. SOM is the most important indicator of fertility of black soil. It provides crops with various nutrients to increase productivity, improves soil microbial diversity, and maintains soil health. In addition, it is an essential sink for the carbon cycle in the terrestrial ecosystem. Therefore, OM enrichment in black soil should be a standing priority.

The SOM content of black soil is affected by many natural and anthropogenic factors. They include soil type [4-6], topography [7,8], climate [9-11], vegetation [12-15], land use [16-18], and so on. The different soil types lead to different soil nutrient losses, which lead to different accumulation of SOM. Topography mainly affects the SOM content by affecting the temperature. Climate factors mainly include temperature and precipitation. Temperature affects SOM content by affecting the degradation of OM by microorganisms and precipitation affects SOM content by affecting the OM accumulation. Vegetation increases the accumulation of SOM by reducing wind erosion of surface soil. The difference of land use affects the quantity and quality of SOM, which further affects the decomposition process of SOM [19].

Recognizing the role of the primary influencing factors is essential to an integrated protection strategy. Many studies analyze the factors influencing SOM and its spatial distribution. Further, correlation analysis [20], geographically weighted regression [21,22], and kriging [23] are the most frequently used methods. On the one hand, SOM's primary factors vary in different regions due to different environments and human activities. Further, the entire northeast black soil zone has not been studied comprehensively. On the other hand, the linear relationship between SOM and the influencing factors is assumed in those methods, and the interactive influence cannot be estimated accurately. Therefore, the factors influencing SOM in the black soil zone of northeast China must be identified accurately using appropriate and effective methods.

The geographical detector model (GDM) proposed by Wang [24] can estimate the linear, nonlinear, and interactive influence of explanatory variables on the target variable based on the coherence of their spatial distribution pattern. The GDM has been widely used in soil science [25-28], ecology [29-32], meteorology [33-35], public health [36-40] and other fields. In this study, the GDM was used to identify the primary factors influencing SOM in the black soil zone of northeast China.

\section{Materials and Methods}

\subsection{Study Area}

The study area is the black soil zone of China $\left(119.42^{\circ}-135.08^{\circ} \mathrm{E}\right.$ and $\left.40.61^{\circ}-52.89^{\circ} \mathrm{N}\right)$ covering 228 counties in the Heilongjiang, Jilin, and Liaoning provinces and the Inner Mongolia Autonomous Region. The location of the study area and SOM concentration is shown in Figure 1. The study area belongs to the cold temperate zone with a mainland monsoon climate. The area is hot and rainy in summer, and cold and dry in winter. This area's annual precipitation is about $500-700 \mathrm{~mm}, 70 \%-90 \%$ of which is concentrated primarily during the growing season from April to September. It is one of the largest black soil zones globally, the most critical grain-producing area of China. There are 18.54 million hectares of cultivated land in this area, with corn, soybeans, and rice as the primary crops. In recent years, severe black soil degradation has drawn national attention, and substantial capital and technology will be invested in this region in the following years.

\subsection{Data Sources}

\subsubsection{SOM Data}

SOM data for 2017 were provided by the Ministry of Natural Resources of China. Each agricultural land plot was assigned a SOM topsoil content $(0-30 \mathrm{~cm})$. The $\mathrm{SOM}$ content was 
derived from county-level soil maps produced by the Chinese Second National Soil Survey in the 1980s and adjusted with supplementary surveys. SOM data quality control follows the Chinese national standard "Regulation for gradation on agriculture land quality". For consistency with the influencing factors' spatial scale, the spatial representation of SOM content in the topsoil was changed from polygons to $1 \mathrm{~km} \times 1 \mathrm{~km}$ pixel. Each pixel's SOM content was calculated as the area-weighted mean of the SOM for all plots located in the pixel, as shown in formula (1).

$$
\mathrm{y}_{\mathrm{g}}=\frac{\sum_{\mathrm{h}=1}^{\mathrm{k}} \mathrm{Y}_{\mathrm{h}} \mathrm{S}_{\mathrm{h}}}{\sum_{\mathrm{h}=1}^{\mathrm{k}} \mathrm{S}_{\mathrm{h}}}
$$

where $y_{\mathrm{g}}$ is the SOM content of pixel $\mathrm{g}, \mathrm{k}$ is the number of plots located within or intersected with the pixel, $Y_{h}$ is the SOM content of plot $h, S_{h}$ is the area of plot $h$ in the pixel (if the plot is totally within the pixel, its area is used; however, if the plot was intersected with the pixel, only the intersection area was counted), as shown in Figure 2. The study area had a total of 145,702 pixels. Pixels without agricultural land were removed. The calculation was conducted in a Hadoop platform, and the same pixel system was used for the influencing factors.

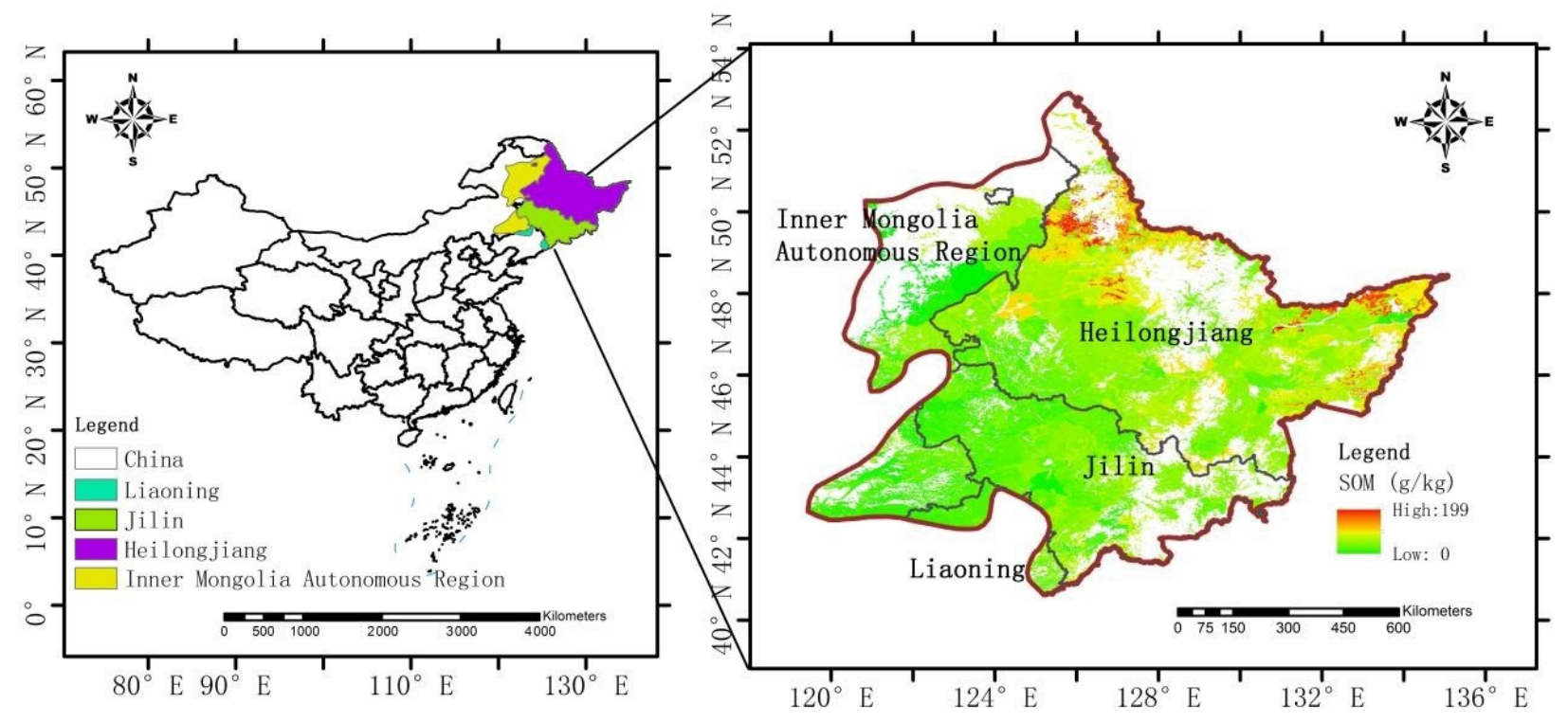

Figure 1. The location of the study area and SOM concentration.

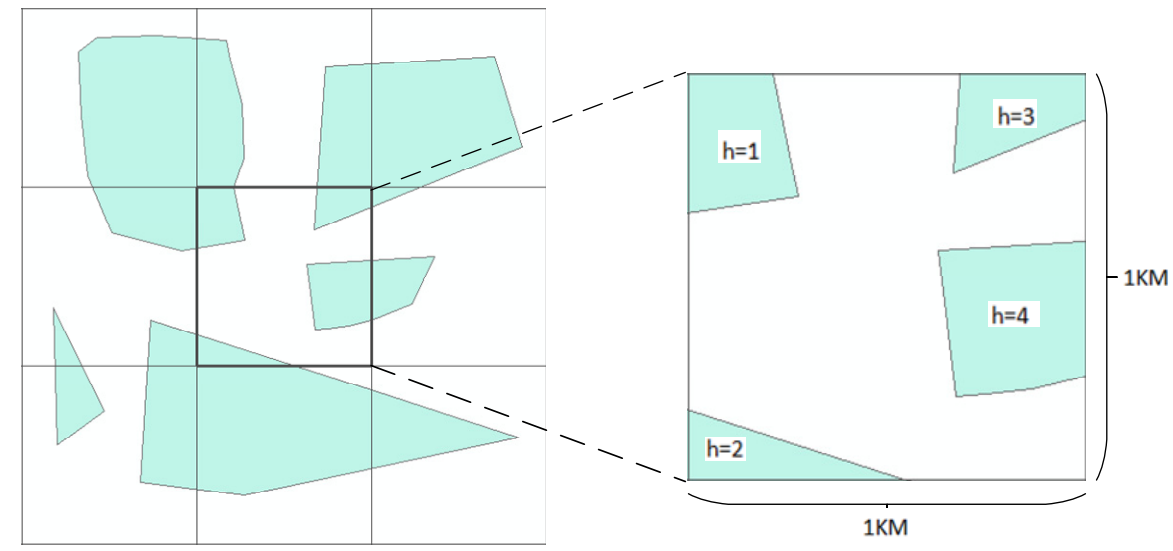

Figure 2. Transferring the spatial support of SOM. 


\subsubsection{Influencing Factors}

When studying the change in SOM in a large scale region, soil microscopic characteristics should not be regarded as influencing factors, and more dominant factors matching the corresponding scale should be considered, such as climate, environment and anthropogenic factors [41]. Nine influencing factors at the regional scale were considered, including geomorphic types (GT), digital elevation model (DEM), soil type (ST), mean annual temperature (MAT), mean annual precipitation (MAP), soil erosion data (SE), pixelized gross domestic product map (GDP), pixelized population map (POP), and land use type (LUT). The data for the nine factors were downloaded from the Resource and Environment Data Cloud Platform, Chinese Academy of Sciences (http:/ / www.resdc.cn (accessed on 10 October 2019)), as shown in Figure 3. The resolution of all data were $1 \mathrm{~km}$. Because the GDM needed to divide the explanatory variables into strata, continuous variables, such as GDP, POP, MAT, MAP, and DEM, were divided into eight classes employing the natural breaks method, which is widely used when the data do not meet the GDM [42]. Each class was treated as one stratum. The classified types were adopted as the strata for the GT, SE, ST, and LUT category variables. Because this study focused only on the SOM in the cultivated land, for LUT, there were only three types, including paddy fields, dry land, and irrigated land. ST was classified according to soil genesis classification criteria; only eight soil types were identified in the 145,702 pixels containing cultivated land. According to Chinese industry standards, "soil erosion classification and classification standards", $\mathrm{SE}$ is divided into 10 classes. According to Chinese national standard "Specifications of classification and coding of geomorphological types", GT is divided into 4 classes. The stratification details for the nine factors are listed in Table 1.

\subsection{Method}

The GDM is a set of statistical methods for detecting spatially stratified heterogeneity and revealing the driving force behind it. This method assumes that if an explanatory variable has an important influence on the target variable, it will have a similar spatial distribution pattern [43]. By analyzing the variances in strata divided by the explanatory variables and the total variance, it does not have a probability distribution and linear relationship assumptions. In this study, the factor detector and interaction detector were used to identify which factors influence SOM and how different factors interact [44]. The GDM software was downloaded from the website http:/ /www.geodetector.cn/ (accessed on 15 October 2019).

\subsubsection{The Factor Detector}

Factor detectors can quantitatively measure the relative importance of influencing factors. Each factor's explanatory power was measured by the $q$-value calculated in formula (2).

$$
q=1-\frac{\sum_{s=1}^{S} n_{s} \delta_{s}^{2}}{N \delta^{2}}
$$

where $S$ is the number of strata separated in an influencing factor, $n_{S}$ is the number of spatial pixels in stratum $s, \delta_{s}^{2}$ is the variance of SOM content in stratum $s, N$ is the total number of spatial pixels in the study area, and $\delta^{2}$ is the variance of SOM content of all pixels of the whole study area. The larger the $q$-value, the stronger the explanatory power of the influence factor for SOM, and vice versa. The significance of the $q$-value can be tested by the non-central $F$ test, as shown in formula (3).

$$
F \sim F(S-1, n-S ; \lambda)
$$

where $F()$ is the non-central $\mathrm{F}$ distribution function, $S$ is the number of strata, $n$ is the sample size, and $\lambda$ is the noncentrality. 

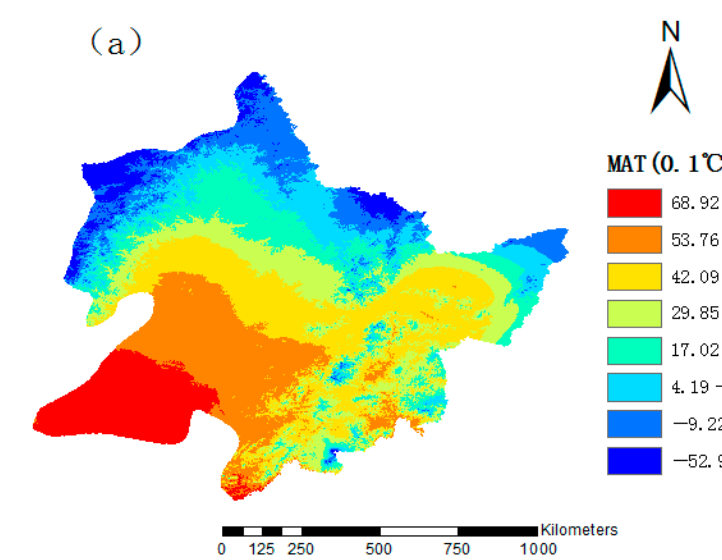

MAT $\left(0.1^{\circ} \mathrm{C}\right)$

\begin{tabular}{|l|l|}
\hline & $68.92-95.75$ \\
$\square$ & $53.76-68.92$ \\
$\square$ & $42.09-53.76$ \\
$\square$ & $29.85-42.09$ \\
$\square$ & $17.02-29.85$ \\
$\square$ & $4.19-17.02$ \\
& $-9.22-4.19$ \\
& $-52.95--9.22$
\end{tabular}

(d)

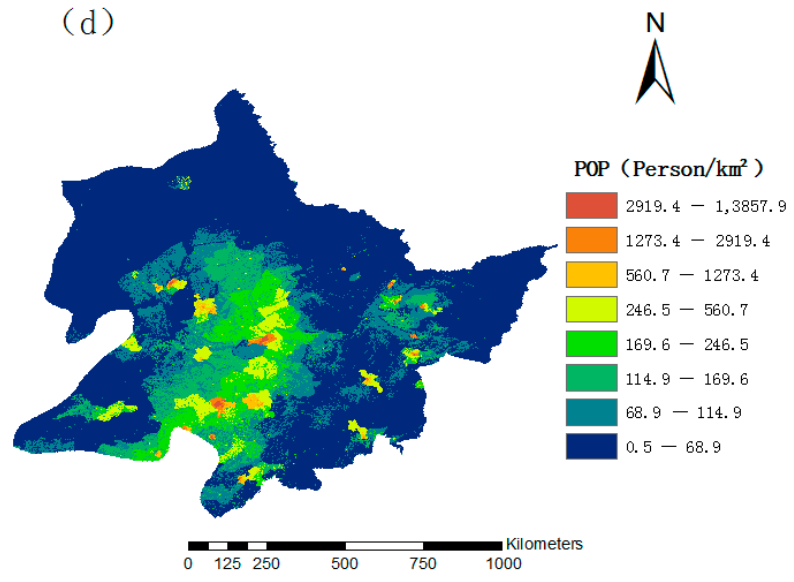

(b)

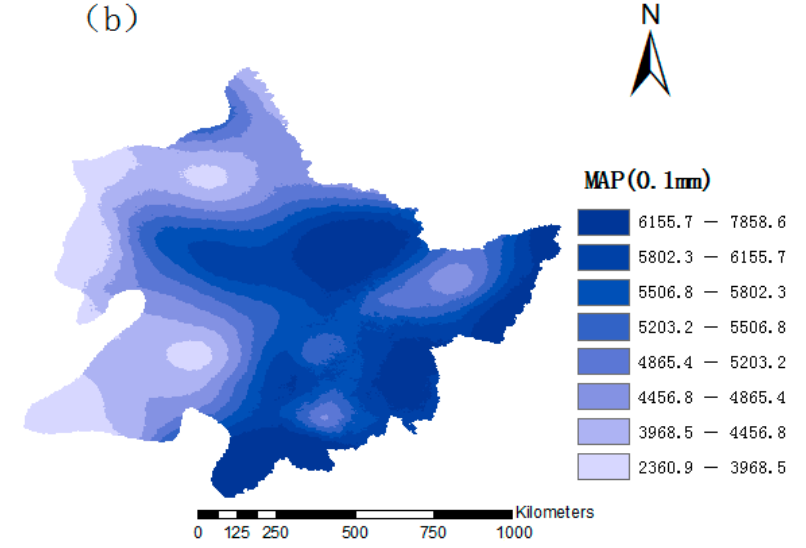

(e)

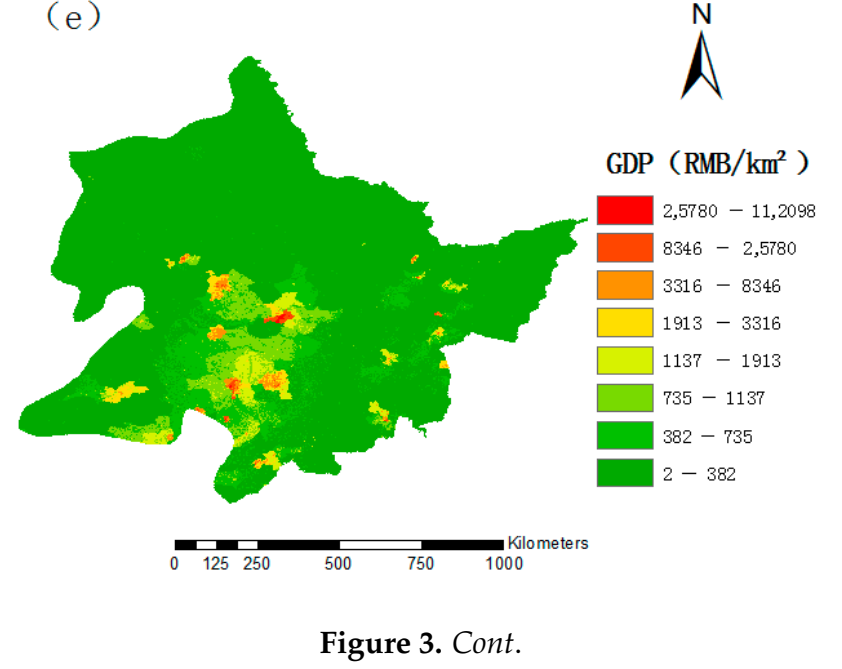

Figure 3. Cont. (c)

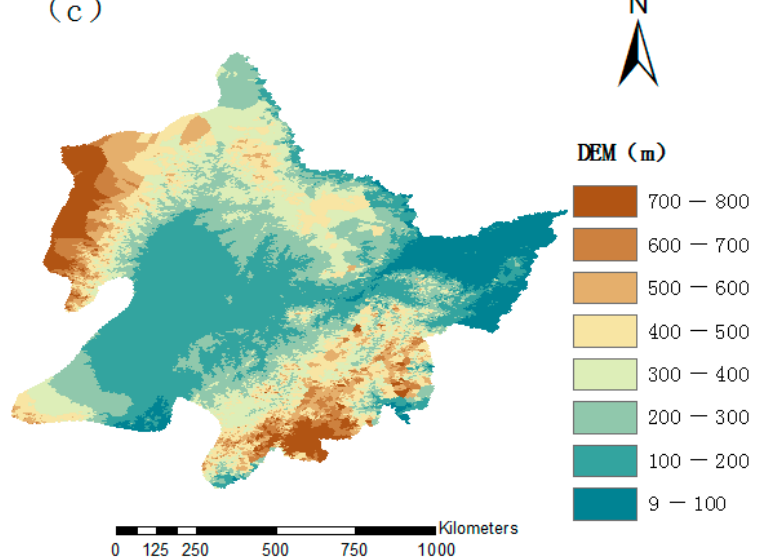

(f)

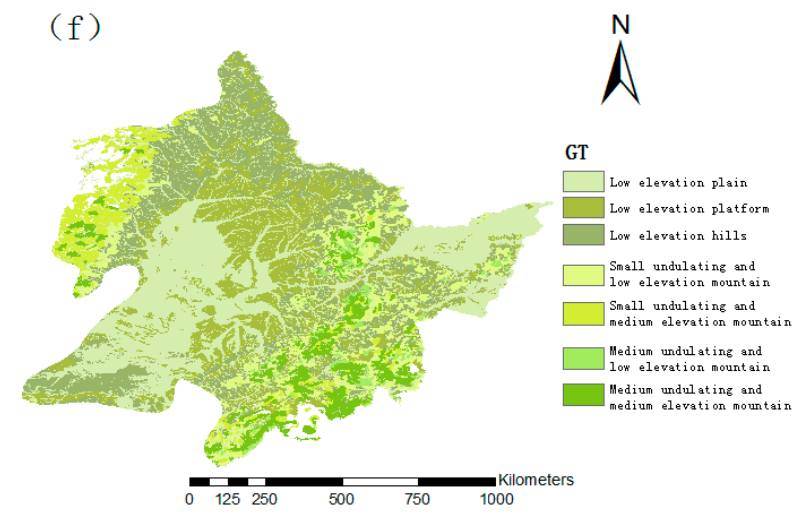



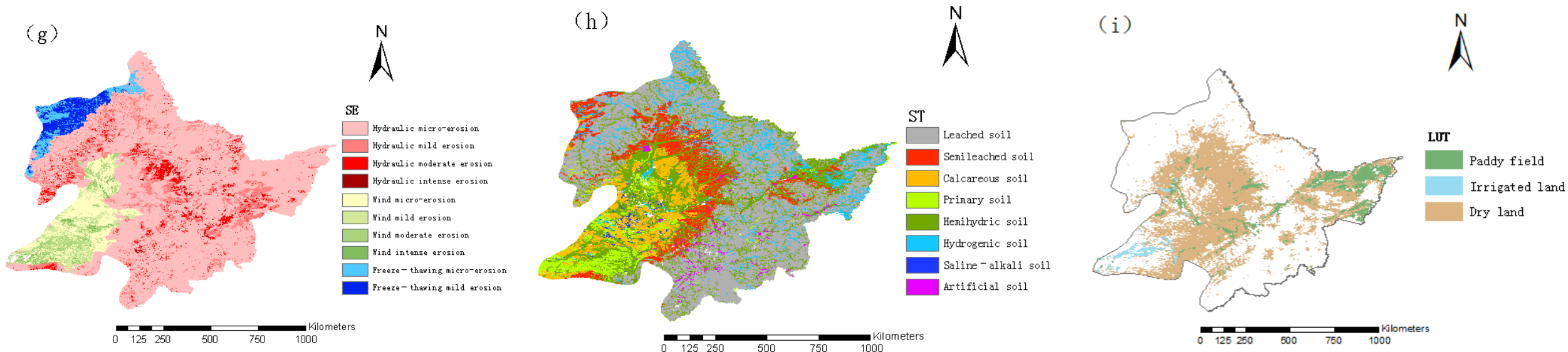

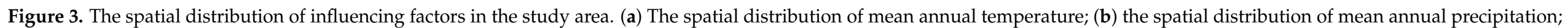

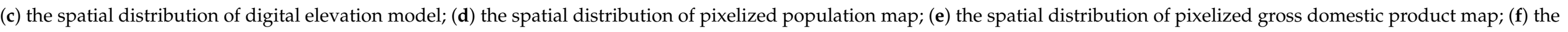
spatial distribution of geomorphic types; (g) the spatial distribution of soil erosion data; (h) the spatial distribution of soil type; (i) the spatial distribution of land use type. 
Table 1. Stratification of influencing factors.

\begin{tabular}{|c|c|c|c|c|c|c|c|c|c|}
\hline Strata No. & Soil Erosion Type & $\begin{array}{c}\text { Digital } \\
\text { Elevation } \\
\text { Model (m) }\end{array}$ & Geomorphic Types & $\begin{array}{l}\text { Mean Annual } \\
\text { Precipitation } \\
\text { (0.1 mm) }\end{array}$ & $\begin{array}{c}\text { Mean Annual } \\
\text { temperature } \\
\left(0.1^{\circ} \mathrm{C}\right)\end{array}$ & Soil Type & $\begin{array}{c}\text { Population } \\
\text { Distribution Data } \\
\left(\text { Person } / \mathbf{k m}^{2}\right)\end{array}$ & $\begin{array}{l}\text { GDP Data } \\
\left(\mathrm{RMB} / \mathrm{km}^{2}\right)\end{array}$ & Land Use Type \\
\hline 1 & Hydraulic micro-erosion & $0-100$ & $\begin{array}{l}\text { Low elevation plain } \\
\text { (LE_plain) }\end{array}$ & $2360.9-3968.5$ & $(-52.95)-(-9.22)$ & Primary soil & $0.5-68.9$ & $2-382$ & Dry land \\
\hline 2 & Hydraulic mild erosion & $100-200$ & $\begin{array}{c}\text { Low elevation platform } \\
\text { (LE_platform) }\end{array}$ & $3968.5-4456.8$ & $(-9.22)$ to 4.19 & Semileached soil & $68.9-114.9$ & $382-735$ & Irrigated land \\
\hline 3 & $\begin{array}{l}\text { Hydraulic moderate } \\
\text { erosion }\end{array}$ & $200-300$ & $\begin{array}{l}\text { Low elevation hill } \\
\text { (LE_hill) }\end{array}$ & $4456.8-4865.4$ & $4.19-17.02$ & Leached soil & $114.9-169.6$ & $735-1137$ & Paddy fields \\
\hline 4 & Hydraulic intense erosion & $300-400$ & $\begin{array}{l}\text { Small undulating and } \\
\text { low elevation mountain } \\
\text { (SULE_mountain) }\end{array}$ & $4865.4-5203.2$ & $17.02-29.85$ & Calcareous soil & $169.6-246.5$ & 1137-1913 & \\
\hline 5 & Wind micro-erosion & $400-500$ & & $5203.2-5506.8$ & $29.85-42.09$ & Hemihydric soil & $246.5-560.7$ & 1913-3316 & \\
\hline 6 & Wind mild erosion & $500-600$ & & $5506.8-5802.3$ & $42.09-53.76$ & Hydrogenic soil & $560.7-1273.4$ & $3316-8346$ & \\
\hline 7 & Wind moderate erosion & $600-700$ & & $5802.3-6155.7$ & $53.76-68.92$ & Saline-alkali soil & $1273.4-2919.4$ & $8346-25780$ & \\
\hline 8 & Wind intense erosion & $700-800$ & & $6155.7-7858.6$ & $68.92-95.75$ & Artificial soil & $2919.4-13,857.9$ & $25,780-112,098$ & \\
\hline 9 & Freeze-thaw micro-erosion & & & & & & & & \\
\hline 10 & Freeze-thaw mild erosion & & & & & & & & \\
\hline
\end{tabular}




\subsubsection{The Interaction Detector}

The interaction detector can identify interactions between different influencing factors. It is based on the detector of individual factors and their combination. For two factors $\mathrm{X} 1$ and $\mathrm{X} 2$, by denoting their unique $q$-values as $\mathrm{q}(\mathrm{X} 1)$ and $(\mathrm{X} 2)$ and the $q$-value by their combination as $\mathrm{q}(\mathrm{X} 1 \cap \mathrm{X} 2)$, the following interactive collusion can be made according to their relationships:

1. If $q(X 1 \cap X 2)<\min (q(X 1), q(X 2))$, the influences of two factors on SOM weaken each other nonlinearly.

2. If $\min (\mathrm{q}(\mathrm{X} 1), \mathrm{q}(\mathrm{X} 2))<\mathrm{q}(\mathrm{X} 1 \cap \mathrm{X} 2)<\max (\mathrm{q}(\mathrm{X} 1), \mathrm{q}(\mathrm{X} 2))$, the influence of one factor on SOM is weakened.

3. If $q(X 1 \cap X 2)>\max (q(X 1), q(X 2))$, the influences of two factors on SOM are mutually enhanced.

4. If $\mathrm{q}(\mathrm{X} 1 \cap \mathrm{X} 2)=\mathrm{q}(\mathrm{X} 1)+\mathrm{q}(\mathrm{X} 2)$, two factors are independent of each other.

5. If $\mathrm{q}(\mathrm{X} 1 \cap \mathrm{X} 2)>\mathrm{q}(\mathrm{X} 1)+\mathrm{q}(\mathrm{X} 2)$, the influences of two factors on SOM are nonlinearly enhanced.

\subsubsection{Impact Analysis}

The GDM can measure the explanatory power of influencing factors but cannot determine whether the influence is positive or negative. The average SOM content within each stratum can be plotted in the radar graph with strata as the axes to analyze each factor's detailed impact. The strata are ordered by corresponding values for the continuous variable to reveal the variation trend of the average SOM content with the rise of influencing factors. For the category variable, the strata are ranked according to the classification method of the types. The elevation and undulation ordered the strata of GT; the strata of SE were ordered first by erosion type and then by erosion intensity. The irrigation conditions ordered the strata of LUT, and the strata of ST were ordered consistent with the principle of soil genesis.

\section{Results}

\subsection{Factor Detector Results}

The results of the factor detector of natural factors and anthropogenic factors are listed in Table 2. All factors have a significant $(p<0.01)$ influence on SOM content. The $q$-value of MAT is the highest among natural factors and is also larger than anthropogenic factors. The $q$-value explains $35.6 \%$ of the spatial heterogeneity of SOM. Following MAT, DEM, ST, and MAP are three primary natural factors influencing SOM content with the explanatory powers of $14.4 \%, 12.6 \%$, and $12.5 \%$. The $q$-values of SE and GT are smaller than 0.1 but are still statistically significant. GDP has the highest $q$-value among anthropogenic factors and is the second highest among all factors. POP also has a high $q$-value and can explain $13.2 \%$ of the spatial heterogeneity of the SOM content. The q-value of LUT is relatively small and reaches $7.5 \%$. Our findings revealed that the main factors affecting SOM are natural factors, and anthropogenic factors also have a certain impact on it.

Table 2. The $q$-values of the factor detector.

\begin{tabular}{cccc}
\hline & Influencing Factor & $q$-Value & $p$-Value \\
\hline & MAT & $35.6 \%$ & $5.49 \times 10^{-10}$ \\
Natural factors & DEM & $14.4 \%$ & $3.47 \times 10^{-10}$ \\
& ST & $12.6 \%$ & $4.55 \times 10^{-10}$ \\
& MAP & $12.5 \%$ & $1.91 \times 10^{-10}$ \\
& SE & $8.0 \%$ & $2.94 \times 10^{-10}$ \\
Anthropogenic factors & GT & $0.6 \%$ & $2.57 \times 10^{-10}$ \\
\hline \multirow{3}{*}{ GDP } & $14.6 \%$ & $6.16 \times 10^{-10}$ \\
& POP & $13.2 \%$ & $7.82 \times 10^{-10}$ \\
& LUT & $7.5 \%$ & $2.71 \times 10^{-10}$ \\
\hline
\end{tabular}




\subsection{The Interaction of Detector Results}

A total of 36 pairs of factors influencing the SOM content of cultivated black soil were obtained. Each pair was greater than that of a single factor, as listed in Table 3. This characteristic means that all factors exerting influence on SOM from different aspects can enhance each other. The combination of MAT and MAP has the highest $q$-value; together, they explain $42.7 \%$ of the SOM content distribution of the study area. This finding is coincident with the conclusion that the distribution of SOM content in northeast China is greatly affected by climatic factors [45]. The $q$-value of the interaction detector results for MAT with other factors are all greater than 0.36 and exceed the interaction of other factors. This finding confirms the importance of MAT for SOM. The combination of MAT and DEM has the second-highest $q$-value; the results show that the combination of MAT and DEM can also have a good effect. Although the temperature decreases as the elevation increases, temperature is not only affected by altitude, but also by other factors, such as latitude. Altitude is not only reflected in temperature, but also in topographic factors, such as the slope. So, the interaction between DEM and MAT can reflect the actual situation more comprehensively. GT is a unique factor. Although the $q$-value of its factor detector is low, the interaction detector with other factors is nonlinearly enhanced. It reveals the fundamental influence of GT, which can magnify the effect of other factors.

Table 3. Influence of the interaction between pairs of factors *

\begin{tabular}{cccccccccc}
\hline & GT & DEM & GDP & POP & ST & MAT & MAP & LUT & SE \\
\hline GT & & Nonl-En & Nonl-En & Nonl-En & Nonl-En & Nonl-En & Nonl-En & Nonl-En & Nonl-En \\
DEM & $16.88 \%$ & & Bi-En & Bi-En & Bi-En & Bi-En & Bi-En & Bi-En & Bi-En \\
GDP & $15.74 \%$ & $24.59 \%$ & & Bi-En & Bi-En & Bi-En & Bi-En & Bi-En & Bi-En \\
POP & $15.46 \%$ & $21.57 \%$ & $18.01 \%$ & & Bi-En & Bi-En & Nonl-En & Bi-En & Nonl-En \\
ST & $15.68 \%$ & $21.28 \%$ & $24.01 \%$ & $22.56 \%$ & & Bi-En & Bi-En & Bi-En & Bi-En \\
MAT & $39.87 \%$ & $41.13 \%$ & $37.15 \%$ & $37.57 \%$ & $39.82 \%$ & & Bi-En & Bi-En & Bi-En \\
MAP & $17.52 \%$ & $28.4 \%$ & $23.96 \%$ & $28.07 \%$ & $24.04 \%$ & $42.74 \%$ & & Bi-En & Bi-En \\
LUT & $8.92 \%$ & $18.16 \%$ & $19.91 \%$ & $18.49 \%$ & $17.74 \%$ & $38.62 \%$ & $16.83 \%$ & & Bi-En \\
SE & $9.67 \%$ & $19.16 \%$ & $22.01 \%$ & $24.1 \%$ & $17.34 \%$ & $39.11 \%$ & $19.18 \%$ & $13.5 \%$ & \\
\hline
\end{tabular}

* "Nonl-En" represents two nonlinearly enhanced factors, "Bi-En" represents two factors that are mutually enhanced.

There are three types of interactions: (1) anthropogenic factors with anthropogenic factors, (2) natural factors with natural factors, and (3) natural factors with anthropogenic factors. The detector results are compared in Figure 4. The interaction between the anthropogenic factors was smaller than the other two types. The combination of natural factors with anthropogenic factors increased the explanatory power on SOM content. The interactions of POP with MAP and SE were all nonlinearly enhanced. This means that population can magnify the influence of natural factors. The interaction between natural factors is also considerable, but the magnification is less than that of natural factors with anthropogenic factors. Based on the interaction detector results, we concluded that to protect SOM, we should adjust land-use activities according to natural conditions and attempt to change natural conditions when possible.

\subsection{Impact Analysis Results}

Based on the factor and interaction detectors that revealed the explanatory power of factors on SOM content, each factor's detailed impacts were analyzed by comparing the SOM content of the different strata. The average SOM content in different strata of all the factors is presented in Figure 5. We found that with the increase in MAT, the SOM content decreased. The reason may be that the high temperature promotes the activity of soil microorganisms and accelerates the decomposition of SOM. However, for the MAP, the more precipitation there is, the higher the SOM content is. Because the northeast black soil zone has less rainfall, water is one factor limiting vegetable growth. The sub-region with a low MAP produces less organic material than consumption, thus reducing SOM. 
For the DEM, the lower the elevation is, the higher the SOM content is. This is inconsistent with the conclusion that the temperature decreases with the increase in altitude, which leads to the increase in SOM content [46]. A reason for this may be that for the elevation of our study area, the maximum is $800 \mathrm{~m}$; the influence of temperature is not significant, which indicates that the main factor in low altitude may be the loss of soil nutrients caused by the slope. According to the GT classification, the undulating terrain ranges from low to high in the form of plain, platform, hill, and mountain. The SOM content also decreases as the terrain undulation increases. This result is consistent with our understanding that rich topsoil at higher elevations is transported to lower elevations due to gravity, rainfall, and erosion. The long-term effect is that SOM at higher altitudes decreases, while SOM at lower altitudes increases.

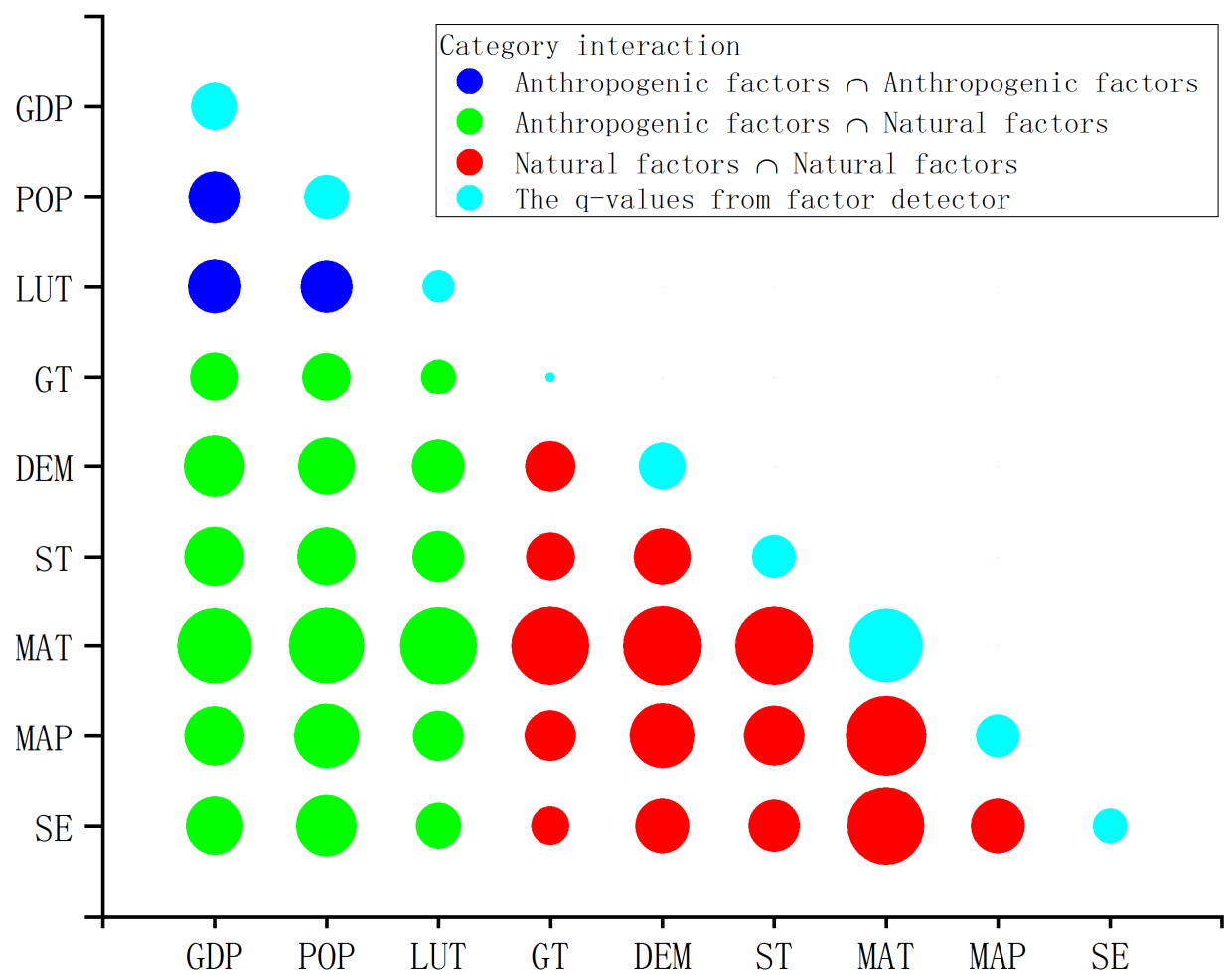

Figure 4. Results of the interaction detector. The size of the circle represents the relative size of the interaction $q$-value of the two factors.

Both wind and water erosion are inversely related to SOM content; the more substantial the erosion intensity, the lower the SOM content. In the study area, SOM content in areas subject to wind erosion is lower than water erosion. The result is that the impact of wind erosion on SOM content is greater than water erosion. Because most precipitation in this area is during the summer when crops are growing, the impact of water erosion is slight. However, it is windy in the spring and winter when most of the land is bare; thus, topsoil can be easily eroded by the wind and sandstorms common in this area.

The OM content in different soil types varies, following the principle of soil genesis. Soils in decreasing order of OM content are hydromorphic soil (marsh soil), leached soil, semi-leached soil, artificial soil, calcareous soil, saline-alkaline soil, and primary soil. The hydromorphic soil has much higher OM than other soil types because water saturation can promote vegetable growth but slow down the decomposition of OM due to the lack of oxygen. In contrast, saline-alkaline soil and primary soil have the lowest OM due to the shortage of input from vegetation. 


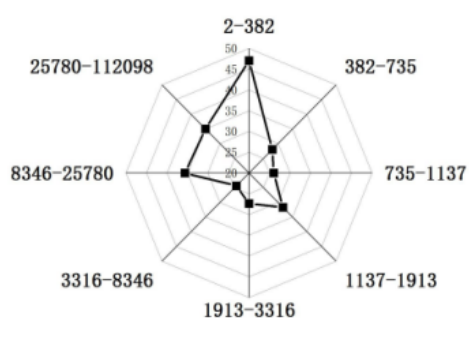

(a) $\mathrm{GDP}\left(\mathrm{RMB} / \mathrm{km}^{2}\right)$

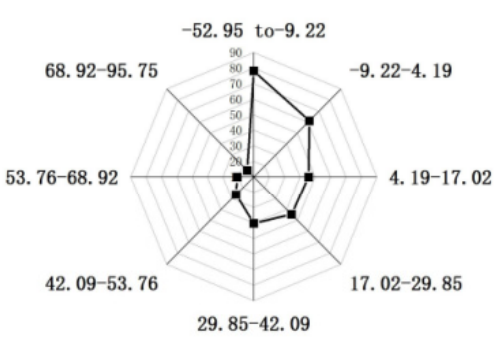

(d) $\operatorname{MAT}\left(0.1^{\circ} \mathrm{C}\right)$

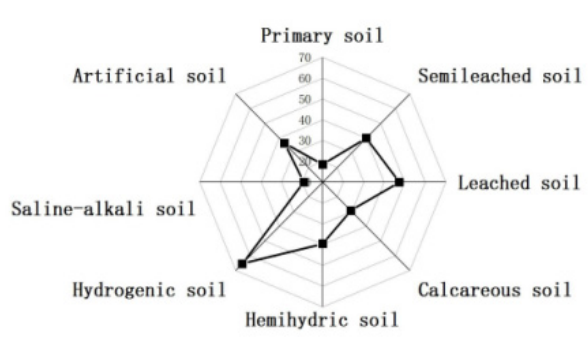

(g) ST

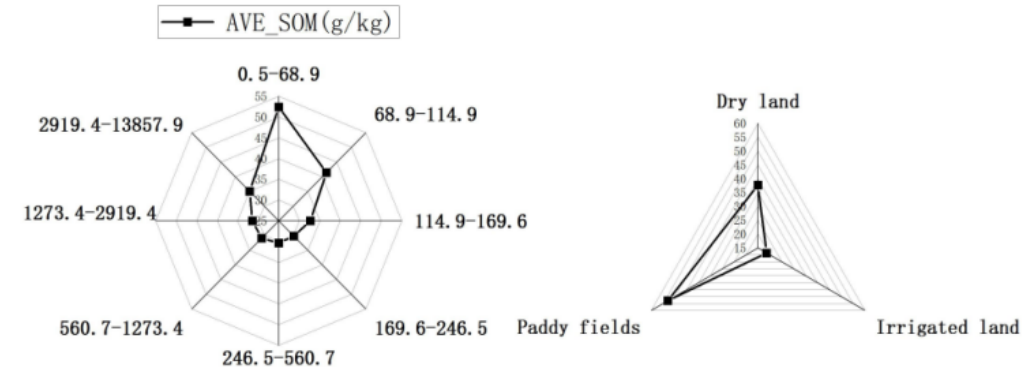

(b) POP (Person $\left./ \mathrm{km}^{2}\right)$

(c) LUT

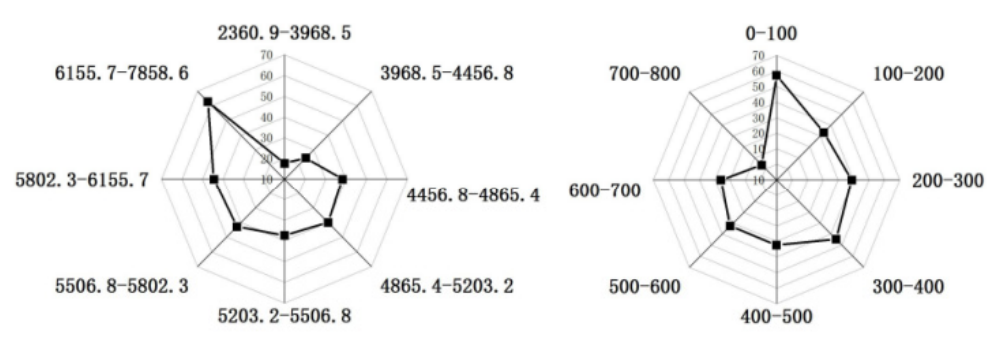

(e) $\operatorname{MAP}(0.1 \mathrm{~mm})$

(f) $\operatorname{DEM}(m)$

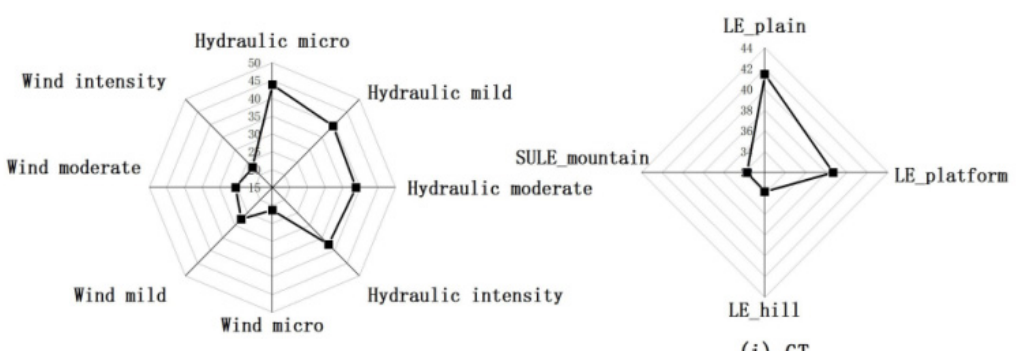

(h) $\mathrm{SE}$

(i) GT

Figure 5. Average SOM values with different grades for all factors. (a) Average SOM values with different grades for pixelized gross domestic product map; (b) average SOM values with different grades for pixelized population map; (c) average SOM values with different grades for land use type; (d) average SOM values with different grades for mean annual temperature; (e) average SOM values with different grades for mean annual precipitation; (f) average SOM values with different grades for digital elevation model; (g) average SOM values with different grades for soil type; (h) average SOM values with different grades for soil erosion data; (i) average SOM values with different grades for geomorphic types.

Among the anthropogenic factors, POP is inversely related to SOM; a denser population means more prolonged and more intense exploration, thus reducing SOM. The relationship between SOM content and GDP is not monotonous. At first, SOM content decreases as GDP increases, but when GDP exceeds 1137, SOM increases. This may be due to the industrial structure. When GDP is low, agriculture is the leading industry; the more output that is produced, the more the soil is used. When GDP is high, manufacturing and service are the leading industries. The higher the GDP, the larger the number of non-agricultural industries; accordingly, there is less pressure on black soil nutrients but more pressure on the soil environment.

In different LUT, paddy fields have the highest SOM content because of their high productivity and low decomposition rate caused by water saturation and the lack of oxygen. Irrigated land has the lowest SOM content, lower than that of dry land. This is expected because the use intensity of irrigated land is much higher than that of dry land when both do not have straw returning. Therefore, straw returning should be encouraged, and converting dry land into irrigated land should be considered with caution. Rainfed farming should also be encouraged because, in this area, the heat and rain are synchronous. 


\section{Discussion}

Using the GDM to identify both linear and nonlinear relationships and interactions, the influence of natural and anthropogenic factors on the SOM of the black soil zone in northeast China was quantitatively analyzed. The findings are consistent with previous studies and provide a quantitative and systematic understanding of the influencing factors [47]. Based on the study results, recommendations for black soil protection are offered.

This study concluded that temperature, elevation, soil type, and land use influence SOM [48]. Among them, MAT has the most significant influence. Although we cannot affect temperature, we can foresee that reducing SOM content will be accelerated by global warming. GDP and POP have the second- and fourth-largest impact on SOM among those factors. Human activities, such as excessive exploitation and unsustainable management practices, play a critical role in the degradation of black soil. DEM and geomorphic characteristics are also important influencing factors. Thus, in mountainous areas, cross-slope ridges and terraces are recommended to retain soil nutrients. SOM varies significantly depending on soil type. Therefore, strict protections should be implemented to prevent the conversion of farmland with fertile soil types to non-farming uses. Further, the protection of land resources and soils with high SOM content should be considered a high priority.

Though wind erosion has more considerable influence than water erosion, both are significant threats to soil productivity. Conservation tillage can effectively control wind erosion by covering the land with stubble and enhancing mechanical soil stability. The Chinese government is promoting conservation tillage in the black soil zone. Until 2020, conservation tillage was practiced on 2.77 million hectares. That area is planned to increase to 9.33 million hectares in 2025 and to 10 million hectares in 2030 [49]. The farmland shelterbelt is another suggested measure to prevent wind erosion.

MAP is positively related to SOM content. Under the condition of abundant rainfall, it is beneficial for the accumulation of SOM to increase vegetation coverage to prevent wind erosion. The rainfall in the study area is relatively little and most of the cultivated land needs irrigation. However, irrigated land has the lowest SOM content among the three types of cultivated land. Under traditional and intense farming practices, irrigation threatens soil fertility. Returning straw for conservation tillage can increase SOM and, at the same time, increase soil permeability and water retention [50]. Hence, conservation tillage can accompany rainfed farming and be appropriately modified based on the local precipitation.

GT had the smallest $q$-values in factor detection. Still, it can nonlinearly enhance the influence of other factors and, therefore, contribute to black soil protection. A variety of measures, such as cross-slope ridges and terraces, should be taken in response to geomorphic characteristics.

The different LUT lead to different changes in SOM. We should pay more attention to LUT, especially under the condition of global warming which is a natural factor that we have no direct control of. For paddy fields, we should adopt the following strategies: turning harrow, building strip fields, mixing sand, and increasing the application of phosphorus and potassium. Adopting the above measures can accelerate soil maturation, improve soil permeability, reduce soil water-retention capacity, promote microbial activity, regulate soil chemical properties, and improve the quality and quantity of SOM. For dry land, it cannot be blindly converted into irrigated land. Rainfed farming should be encouraged in the study area.

In addition to the influencing factors selected in this paper, the influence of different types of agricultural management practice on SOM is also very great, which is the main factor to be considered for the cultivation methods in the study area. Stubble, crop rotation and straw returning are common tillage measures in the study area [51]. Crop stubble covers the surface, reduces the contact between microorganisms and organic matter in the soil, stabilizes the content of SOM, effectively inhibits soil hyperventilation and prevents soil erosion. The rotation cultivation of soybean and red bean has an obvious effect on soil erosion control on the slope surface of the northeast, thin-layer black soil area. 
Straw returning to the field has the good effect of reducing soil erosion and can make the soil nutrient cycle complete, increase the soil microbial diversity, and more importantly, realize carbon sequestration through the input of the soil carbon pool. It is a sustainable agricultural carbon sequestration measure. The above cultivation methods combined with chemical fertilizer can also improve soil structure, increase crop yield and slow down soil failure [52]. A reasonable choice of appropriate cultivation methods will be the main problem in practice. In summary, black soil protection requires advanced conservation methods, farmers' cooperation, and the support of policymakers [53].

\section{Conclusions}

By using the GDM, this study quantitatively analyzed the factors influencing the topsoil's SOM content in the black soil zone of northeast China. The following conclusions were drawn:

1. The nine factors analyzed have a significant relationship with the SOM content. In descending order of intensity, those factors include temperature, GDP, elevation, population, soil type, precipitation, soil erosion, land-use type, and geomorphic type.

2. The interaction of any two factors enhanced their influence on SOM content; the most influential combinations include MAT + MAP $(\mathrm{q}=0.43), \mathrm{DEM}+$ MAT $(\mathrm{q}=0.41)$, MAT + GT ( $=0.40)$, MAT + ST ( $=0.40)$, and MAT + LUT ( $=0.39)$.

3. With increases in MAT, POP, SE, DEM, and terrain undulation, SOM content decreases. At the same time, SOM content is positively affected by MAP. Wind erosion has more significant impacts on SOM content than water erosion in the study area. When GDP is less than 1137, it is negatively related to SOM content. However, when GDP is greater than 1173, the correlation is positive. SOM content varies by soil type, following the principle of soil genesis, which is related to other natural factors, such as topography, parent material, climate, organism and age of soil. Hydromorphic soil, leached soil, and semi-leached soil are fertile. Among the three types of tillage, SOM content declines from high to low in paddy fields, dry land, and irrigated land.

This study demonstrated that both natural factors and anthropogenic activities have effects on SOM. The main influencing factors are natural factors; anthropogenic activities are in 5th position in the factors of influence, analyzed by pairs. However, natural factors are hard to change, so we should pay more attention to anthropogenic activities. Excessive exploitation and unsustainable management practices should be avoided. Sustainable practices, such as conservation tillage, farmland shelterbelts, cross-slope ridges, terraces, and rainfed farming, should be adopted and adjusted based on local conditions. Finally, strict measures to prevent the conversion of high-quality farmland to non-farm uses should be adopted and enforced.

Author Contributions: Conceptualization, Bingbo Gao, Jianyu Yang, Bayartungalag Batsaikhan, Battogtokh Dorjgotov, Wenju Yun and Dehai Zhu; data curation, Cong Ou and Zhenrong Du; formal analysis, Zhenbo Du and Bingbo Gao; funding acquisition, Bayartungalag Batsaikhan and Battogtokh Dorjgotov; methodology, Zhenbo Du; resources, Wenju Yun; software, Zhenbo Du; supervision, Bingbo Gao and Dehai Zhu; validation, Zhenrong Du; visualization, Cong Ou; writing-original draft, Zhenbo Du; writing - review and editing, Bingbo Gao and Jianyu Yang. All authors have read and agreed to the published version of the manuscript.

Funding: This research was supported by the National Key Research and Development Program of China (2016YFD0800903, 2021YFE0102300).

Institutional Review Board Statement: Not applicable.

Informed Consent Statement: Not applicable.

Acknowledgments: We are grateful for the comments of the anonymous reviewers, which greatly improved the quality of this paper.

Conflicts of Interest: The authors declare no conflict of interest. 


\section{References}

1. Xie, H.; Shi, F.U.; Zhang, X.; Wang, J. Review on Characterization of SOM Stabilization and Affecting Factors. Chin. J. Soil Sci. 2003, 34, 459-462.

2. He, Y.; Zhang, B.; Li, F.; Ma, C. The problems of agro-ecological environment and the countermeasures in black soil zone in Northeast China. Agric. Res. Arid Areas 2004, 22, 191-194.

3. Guo, W. Establishing "special zone for cultivated land protection" and rationally developing and utilizing black soil layer. Land Resour. Inf. 2007, 12, 35-38.

4. Moeckel, C.; Nizzetto, L.; Guardo, A.D.; Steinnes, E.; Freppaz, M.; Filippa, G.; Camporini, P.; Benner, J.; Jones, K.C. Persistent organic pollutants in boreal and montane soil profiles: Distribution, evidence of processes and implications for global cycling. Environ. Sci. Technol. 2008, 42, 8374-8380. [CrossRef]

5. Chen, T.; Chang, Q.; Liu, J.; Clevers, J.G. Spatio-temporal variability of farmland soil organic matter and total nitrogen in the southern Loess Plateau, China: A case study in Heyang County. Environ. Earth Sci. 2016, 75, 28. [CrossRef]

6. Barre, P.; Durand, H.; Chenu, C.; Meunier, P.; Montagne, D.; Castel, G.; Billiou, D.; Soucemarianadin, L.; Cecillon, L. Geological control of soil organic carbon and nitrogen stocks at the landscape scale. Geoderma 2017, 285, 50-56. [CrossRef]

7. Singh, N.J.; Kudrat, M.; Jain, K. Effect of Land Use and Topography on Spatial Distribution of Soil Organic Carbon in Semi-arid Subtropical Ecosystems in Uttar Pradesh, India. Int. J. Ecol. Environ. Sci. 2014, 40, 189-197.

8. Yu, H.; Zha, T.; Zhang, X.; Nie, L.; Pan, Y.J.C. Spatial distribution of soil organic carbon may be predominantly regulated by topography in a small revegetated watershed. Catena 2020, 188, 104459. [CrossRef]

9. Shevtsova, L.; Romanenkov, V.; Sirotenko, O.; Smith, P.; Rodionova, V. Effect of natural and agricultural factors on long-term soil organic matter dynamics in arable soddy-podzolic soils-Modeling and observation. Geoderma 2003, 116, 165-189. [CrossRef]

10. Dai, W.; Huang, Y. Relation of soil organic matter concentration to climate and altitude in zonal soils of China. Catena 2006, 65, 87-94. [CrossRef]

11. Jiménez-González, M.A.; Lvarez, A.M.; Carral, P.; Almendros, G.J.C. Influence of soil forming factors on the molecular structure of soil organic matter and carbon levels. Catena 2020, 189, 104501. [CrossRef]

12. Yang, L.; Shen, F.; Zhang, L.; Cai, Y.; Zhou, C. Quantifying influences of natural and anthropogenic factors on vegetation changes using structural equation modeling: A case study in Jiangsu Province, China. J. Clean. Prod. 2021, 280, 124330. [CrossRef]

13. Lorenz, M.; Sören, T.B. Tree species affect soil organic matter stocks and stoichiometry in interaction with soil microbiota. Geoderma 2019, 353, 35-46. [CrossRef]

14. Resende, T.M.; Rosolen, V.; Bernoux, M.; Moreira, M.Z.; da Conceição, F.T.; Govone, J.S. Dynamics of soil organic matter in a cultivated chronosequence in the Cerrado (Minas Gerais, Brazil). Soil Res. 2017, 55, 750-757. [CrossRef]

15. Kong, X.S.; Luan, R.J.; Miao, Y.; Qi, S.H.; Li, F. Polycyclic aromatic hydrocarbons in sediment cores from the Dashiwei Tiankeng reach in the Bailang underground river, South China. Environ. Earth Sci. 2015, 73, 5535-5543. [CrossRef]

16. Fan, M.; Lal, R.; Zhang, H.; Margenot, A.J.; Wu, J.; Wu, P.; Zhang, L.; Yao, J.; Chen, F.; Gao, C. Variability and determinants of soil organic matter under different land uses and soil types in eastern China. Soil Tillage Res. 2020, 198, 104544. [CrossRef]

17. Wang, T.; Camps-Arbestain, M.; Hedley, C.J.A.E. Factors influencing the molecular composition of soil organic matter in New Zealand grasslands. Agric. Ecosyst. Environ. 2016, 232, 290-301. [CrossRef]

18. Schulp, C.J.E.; Veldkamp, A. Long-term landscape-Land use interactions as explaining factor for soil organic matter variability in Dutch agricultural landscapes. Geoderma 2008, 146, 457-465. [CrossRef]

19. Schillaci, C.; Acutis, M.; Lombardo, L.; Lipani, A.; Fantappie, M.; Märker, M.; Saia, S. Spatio-temporal topsoil organic carbon mapping of a semi-arid Mediterranean region: The role of land use, soil texture, topographic indices and the influence of remote sensing data to modelling. Sci. Total Environ. 2017, 601-602, 821-832. [CrossRef]

20. Hu, K.; Wang, S.; Li, H.; Huang, F.; Li, B. Spatial scaling effects on variability of soil organic matter and total nitrogen in suburban Beijing. Geoderma 2014, 226-227, 54-63. [CrossRef]

21. Costa, E.M.; Tassinari, W.D.; Pinheiro, H.S.; Beutler, S.J.; Dos Anjos, L.H. Mapping Soil Organic Carbon and Organic Matter Fractions by Geographically Weighted Regression. J. Environ. Qual. 2018, 47, 718-725. [CrossRef]

22. Zeng, C.; Yang, L.; Zhu, A.X.; Rossiter, D.G.; Liu, J.; Liu, J.; Qin, C.; Wang, D.J.G. Mapping soil organic matter concentration at different scales using a mixed geographically weighted regression method. Geoderma 2016, 281, 69-82. [CrossRef]

23. $\mathrm{Hu}, \mathrm{K}$; Li, H.; Li, B.; Huang, Y. Spatial and temporal patterns of soil organic matter in the urban-rural transition zone of Beijing. Geoderma 2007, 141, 302-310. [CrossRef]

24. Wang, J.-F.; Zhang, T.-L.; Fu, B.-J. A measure of spatial stratified heterogeneity. Ecol. Indic. 2016, 67, 250-256. [CrossRef]

25. Zhao, Y.; Deng, Q.; Lin, Q.; Zeng, C.; Zhong, C.J.E.P. Cadmium source identification in soils and high-risk regions predicted by geographical detector method. Environ. Pollut. 2020, 263, 114338. [CrossRef] [PubMed]

26. Su, Y.; Li, T.; Cheng, S.; Wang, X.J.E.E. Spatial distribution exploration and driving factor identification for soil salinisation based on geodetector models in coastal area. Ecol. Eng. 2020, 156, 105961. [CrossRef]

27. Qiao, P.; Yang, S.; Lei, M.; Chen, T.; Dong, N. Quantitative analysis of the factors influencing spatial distribution of soil heavy metals based on geographical detector. Sci. Total Environ. 2019, 664, 392-413. [CrossRef]

28. Tao, H.; Liao, X.; Li, Y.; Xu, C.; Zhu, G.; Cassidy, D.P. Quantifying influences of interacting anthropogenic-natural factors on trace element accumulation and pollution risk in karst soil. Sci. Total Environ. 2020, 721, 137770. [CrossRef] 
29. Cheng, H.; Qiong, X.U.; University, H.N. Study on the Coupling Relationship of Urbanization-Tourism-Ecology in China Based on Geographical Detector. J. Zhongzhou Univ. 2019, 36, 21-27.

30. He, J.; Pan, Z.; Liu, D.; Guo, X. Exploring the regional differences of ecosystem health and its driving factors in China. Sci. Total Environ. 2019, 673, 553-564. [CrossRef]

31. Fan, H.; Wang, J.; Hu, M.; Li, Z.; Jiang, X.; Wang, J. Spatiotemporal assessment of marine environmental monitoring programme based on DIN concentration in the Yangtze River estuary and its adjacent sea. Sci. Total Environ. 2020, 707, 135527. [CrossRef] [PubMed]

32. Lin, H.Y.; Tseng, Y.H.; Hsieh, C.F.; Hu, J.M. Geographical distribution of dioecy and its ecological correlates based on fine-scaled species distribution data from a subtropical island. Ecol. Res. 2019, 35, 170-181. [CrossRef]

33. Liu, Z.; Wang, S.; Zhang, Y.; Xiang, J.; Tong, M.X.; Gao, Q.; Zhang, Y.; Sun, S.; Liu, Q.; Jiang, B.J.E.S.; et al. Effect of temperature and its interactions with relative humidity and rainfall on malaria in a temperate city Suzhou, China. Environ. Sci. Pollut. Res. 2021, 28, 16830-16842. [CrossRef] [PubMed]

34. Jiang, Y.; Yin, X.; Wang, X.; Zhang, L.; Chen, F.J.A.J. Impacts of global warming on the cropping systems of China under technical improvements from 1961 to 2016. Agron. J. 2020, 113, 187-199. [CrossRef]

35. Zhao, W.; Hu, Z.; Guo, Q.; Wu, G.; Chen, R.; Li, S. Contributions of climatic factors to inter-annual variability of vegetation index in northern China grasslands. J. Clim. 2019, 33, 175-183. [CrossRef]

36. Fang, F.; Ma, L.; Fan, H.; Che, X.; Chen, M. The spatial differentiation of quality of rural life based on natural controlling factors: A case study of Gansu Province, China. J. Environ. Manag. 2020, 264, 110439. [CrossRef]

37. Raposo, V.; Ferreira, P.; Tavares, A. Differences in Portuguese primary care quality: An analysis using geographical and patient satisfaction data. Eur. J. Public Health 2019, 29, ckz034.018. [CrossRef]

38. Huang, R.; Ning, H.; He, T.; Bian, G.; Hu, J.; Xu, G. Impact of PM 10 and meteorological factors on the incidence of hand, foot, and mouth disease in female children in Ningbo, China: A spatiotemporal and time-series study. Environ. Sci. Pollut. Res. 2019, 26, 17974-17985. [CrossRef] [PubMed]

39. Zhang, X.X.; Xu, C.D.; Xiao, G.X. Spatial heterogeneity of the association between temperature and hand, foot, and mouth disease risk in metropolitan and other areas. Sci. Total Environ. 2020, 713, 136623. [CrossRef]

40. Xu, C.; Zhang, X.; Xiao, G. Spatiotemporal decomposition and risk determinants of hand, foot and mouth disease in Henan, China. Sci. Total Environ. 2019, 657, 509. [CrossRef] [PubMed]

41. Wu, L.; Cai, Z. The Relationship between the Spatial Scale and the Variation of Soil Organic Matter in China. Adv. Earth Sci. 2006, 21, 965-972.

42. Yang, S.P.; Han, H.D. Quantitative analysis of NDVI driving factors in Gansu Province based on geodetector. J. Gansu Agric. Univ. 2019, 54, 115-123.

43. Wang, J.F.; Hu, Y. Environmental health risk detection with GeogDetector. Environ. Model. Softw. 2012, 33, 114-115. [CrossRef]

44. Wang, J.F.; Li, X.H.; Christakos, G.; Liao, Y.L.; Zhang, T.; Gu, X.; Zheng, X.Y. Geographical Detectors-Based Health Risk Assessment and its Application in the Neural Tube Defects Study of the Heshun Region, China. Int. J. Geogr. Inf. Sci. 2010, 24, 107-127. [CrossRef]

45. Shuqin, S.; Qiwen, C.; Zhengguo, L.I.; Hengzhou, X.U.; Management, S.O.; University, T.P. Influence of spatial heterogeneity of climatic and socio-economic factors on soil organic matter-A case study of the central Heilongjiang Province, China. Chin. J. Eco-Agric. 2014, 22, 1102-1112.

46. Li, Q.; Cheng, X.; Luo, Y.; Xu, Z.; Xu, L.; Ruan, H.; Xu, X. Consistent temperature sensitivity of labile soil organic carbon mineralization along an elevation gradient in the Wuyi Mountains, China. Appl. Soil Ecol. 2017, 117-118, 32-37. [CrossRef]

47. Fan, Z.; Peng, C.; Jin, R.; Wu, H. Main Soil Types in Northeast China and Fertility Index Correlation with Meteorological Factors. J. Maize Sci. 2018, 26, 140-146.

48. Wiesmeier, M.; Urbanski, L.; Hobley, E.U.; Lang, B.; Kgel-Knabner, I. Soil organic carbon storage as a key function of soils-A review of drivers and indicators at various scales. Geoderma 2019, 333, 149-162. [CrossRef]

49. Dongmin, D. Adding energy and momentum for the high quality development of agricultural mechanization-Written on the occasion of the release of the "northeast black soil conservation tillage action plan". Agric. Mach. Qual. Superv. 2020, 184, 9-10.

50. Miao, X.; Ye, S.; Han, Z.; Ding, X.; Yuan, H.; Zhao, G.; Jin, W. Research Review of the Effect for Carbon Sequestration Under No-tillage Agriculture. Chin. Agric. Sci. Bull. 2014, 030, 32-39.

51. Xu, X.; Sui, Y.; Zhang, Y.; Wang, Y.; Liu, M.; Liu, Y. Effects of different tillages on the soil and water conservation benefits in Northeast black soil area of China. Sci. Soil Water Conserv. 2013, 11, 12-16.

52. Wang, R.; Zhang, J.; Dong, S.; Liu, P. Present situation of maize straw resource utilization and its effect in main maize production regions of China. Chin. J. Appl. Ecol. 2011, 22, 1504-1510.

53. Minasny, B.; Malone, B.P.; Mcbratney, A.B.; Angers, D.A.; Winowiecki, L.A. Soil Carbon 4 per mille. Geoderma 2017, 292, 59-86. [CrossRef] 